\title{
Clinton team wonders if FCCSET is broken
}

\begin{abstract}
Washington. The Clinton administration is slowly turning its attention to the $\$ 14$ billion that the US government will spend this year on basic research, conducting a review of six multi-billion-dollar interagency initiatives and convening a panel of senior administrators to draw up programmes for future budgets that correspond to the president's domestic policy goals.
\end{abstract}

\section{Six research themes in the 1994 budget}

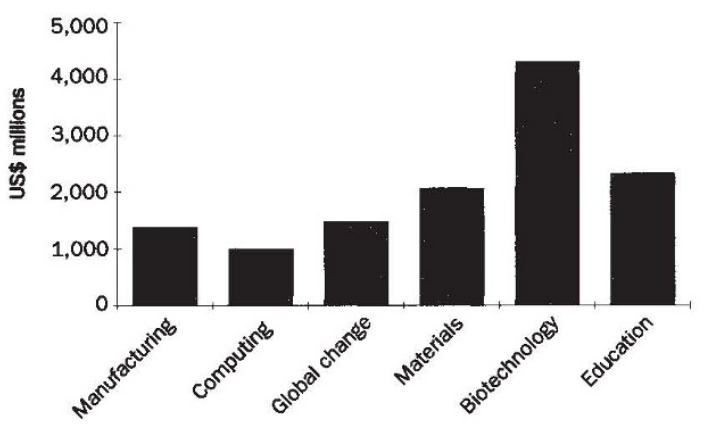

The leading players:

Manufacturing: DOD, DOE, DOC, NSF

Computing DOD, NSF, DOE, NASA

Global change: NASA, NSF

Materials: $\quad$ DOE, DOD, NSF

Biotechnology: HHS, DOE, NSF, USDA

Education: NSF, DOD, HHS, ED

DOD: Department of Defense, USDA: US Department of Agriculture, DOC: Department of Commerce, DOE: Department of Energy, ED: Department of Education, HHS: Health and Human Services, NASA: National Aeronautics and Space Administration, NSF: National Science Foundation

Despite the political rhetoric about change, the budget that President Bill Clinton proposed on 8 April for fiscal year 1994, which begins on 1 October 1993, makes only minor alterations in the way in which the government invests in basic research. Even the economic stimulus package that Congress defeated last week, which contained nearly half a billion dollars for the National Science Foundation (NSF), the National Institutes of Standards and Technology and other federal research agencies (see right), would at best have strengthened existing programmes rather than charting new directions.

One sign that the administration is beginning to think seriously about basic research is its decision last week to release only partial information on six interagency initiatives that, taken together, will cost $\$ 12.5$ billion. Previously, each initiative on advanced materials, manufacturing technology, biotechnology, high-performance computing, global climate change and science education - was described in a pamphlet of a hundred pages or more that included detailed budgets of what each agency planned to spend. This year, in contrast, the White House Office of Science and Technology Policy (OSTP) issued a slim volume containing a four-page summary of each programme.

John Gibbons, the president's science adviser and OSTP director, says that the six FCCSET (pronounced 'fix-it') initiatives, named after the Federal Coordinating Committee on Science, Engineering and Technology that supervises them, are "a dynamic list of topics" that are being reexamined for their contribution to national economic growth. For example, he points out that the four-year-old global change programme began as an attempt to "understand the scientific processes. Now we are trying to shift attention towards its potential impact on the economy."

The search for practical results as well as for good science stems from the administration's desire to use technology to revive the US economy as well as from the fact that the initiatives have grown large enough to attract the attention of Congress. "In the past three years we have provided NSF with $\$ 600$ million for the high-performance computing initiative", says Kevin Kelly, an aide to Senator Barbara Mikulski (Democrat, Maryland), who is chair of the appropriations subcommittee that controls the budgets of NSF,

NASA, the Environmental Protection Agency and several other agencies. "What have we bought with that money? I think that NSF would have a hard time answering that question."

The largest FCCSET initiative, some $\$ 4.3$ billion for biotechnology, is also the most troubled. Although the initiative includes programmes operated by the agriculture, energy and defence departments as well as by NSF and NASA, more than threequarters of its budget is controlled by the National Institutes of Health (NIH), which is primarily interested in funding healthrelated basic research. As a result, efforts to focus attention on environmental issues, for example bioremediation or bioprocessing, have met with limited success. In addition, the administration has requested a 1994 budget for NIH that is essentially flat, leading one NIH official to point out that "if you don't get any more money, then it's superfluous to talk about new initiatives".

Gibbons's predecessor, D. Allan Bromley, believed that the government could carry out no more than five or six major initiatives at once because of the time and resources required to coordinate activities among as many as a dozen agencies. Although Gibbons has not said whether he agrees with that analysis, he has talked about "a rotation" in which new programmes replace older initiatives.

One proposal, in the works for the past two years but delayed by the change in administration, would deal with coastal ocean zones. Officials at the National Oceanic and Atmospheric Administration (NOAA) have already done an inventory of existing research programmes and begun to plan an interdisciplinary, global strategy to address issues ranging from non-point sources of pollution to sustainable development. But a meeting last December was canceled by the outgoing Bush administration, and NOAA officials are waiting to hear if the Clinton administration wants to pursue the matter.

That decision - and many others involving the course of science over the next four years - may rest with a new group of

\section{Research budgets suffer with defeat of stimulus plan}

Washington. The defeat of the economic stimulus package proposed by US President Bill Clinton means that the National Science Foundation (NSF) is unlikely to receive anything close to its 1994 budget request. The stimulus plan contained \$207 million for NSF in the current year, nearly half of the increase of 15 per cent being sought for fiscal year 1994, which begins on 1 October; without that running start, Congress is extremely unlikely to give NSF such a large increase in the face of pressure to reduce the federal deficit and to fund other domestic programmes.

At the same time, two other research programmes that stood to benefit handsomely from the stimulus plan - the $\$ 103$ million proposed for the Advanced Technology Program (ATP) within the Department of Commerce and $\$ 47$ million sought for cooperative research agreements between industry and the national laboratories in the Department of Energy - are expected to remain important priorities for the Clinton administration and to enjoy rising budgets in 1994 despite the temporary setback in Congress. In the short run, ATP officials say they will cancel plans for another round of applications this summer to their programme, which funds proposals from individual companies and industry consortia, while the Energy Department expects to continue its emphasis on funding research projects within the laboratories that also serve the needs of industry. 
about 30 senior administrators convened two weeks ago by Gibbons and Bowman Cutter of the National Economic Council. The so-called deputies' science and technology working group was asked to nominate people within their agencies to serve on panels that will develop policies for 15 topics ranging from specific issues such as medical technology to basic research itself. The goal of the group, according to Tim Newell of OSTP, is to propose specific ways to carry out the president's technology initiative announced in February, but the group is also expected to make recommendations for programmes to be included in the budget for fiscal year 1995 that will be submitted to Congress next winter.

Part of the reason for the uncertainty surrounding the new administration's plans for science are the large number of unfilled positions at OSTP and the ambiguous relationship between it and the office of Vice President $\mathrm{Al}$ Gore, the leading figure within the administration on technology issues. Gibbons is believed to be planning a realignment of portfolios, elevating the environment and lowering the life sciences in the OSTP hierarchy, but only one of his choices for the four vacant associate directorships has as yet been cleared by the White House and nominated by the president.

Jeffrey Mervis

\section{Britain backs down over threat to run universities}

London. The British government has backed down under pressure from the House of Lords over a controversial proposal that would have given the Secretary of State for Education formal responsibility for the way in which universities are run (see Nature 362, 275; 1993).

The government had argued that its proposal to include words expressing the minister's responsibility for further and higher education in a new bill would have had little impact, because the main thrust of the bill in question was changes in the administration of schools. However in a parliamentary debate last week, members of the House of Lords, reflecting concerns expressed by many university vice-chancellors, claimed that the offending clause could be used to justify direct intervention by the government in university administration - and was, as such, an infringement on academic freedom.

Baroness Blatch, minister of state in the Department for Education, announced that the government had agreed to withdraw its proposal and that she would seek discussions with its critics on a more acceptable formulation of the secretary of state's responsibilities.

David Dickson

\section{Choice to head NIST defines shift in US technology policy}

San Francisco \& Washington. The nomination of Arati Prabhakar as director of the US National Institutes of Standards and Technology (NIST) clearly shows the contrast between the views of President Bill Clinton and former President George Bush on industrial policy.

Three years ago, Craig Fields was forced out as director of the Defense Advanced Research Projects Agency (DARPA) after Prabhakar, then deputy director of DARPA's defence sciences office, made a $\$ 4$ million investment in Gazelle Microcircuits Inc., a tiny Silicon Valley semiconductor company that makes high-speed gallium arsenide chips. The agreement angered the Bush administration, which was philosophically opposed to the government becoming a venture capitalist for fledgling companies. Although the government eventually decided to accept royalties from sales of the chip rather than to take an equity share in the company, it was widely seen as the last straw in a conflict between Fields and the administration.

Now Prabhakar, a 34-year-old applied physicist, is poised to become head of NIST, to which the Clinton administration has given a leading role in stimulating the US economy. Not surprisingly, her former boss is delighted by her promotion.

"She is a very, very capable manager", says Fields, chief executive officer of the industry-led Microelectronics Computer Consortium in Austin, Texas. "She's innovative and she understands new technology and how to apply it."

Although Gazelle's technology was impressive, the company was unable to survive on its own. In 1991, a year after the Pentagon's investment, Gazelle merged with two other chip makers, TriQuint Semiconductor of Beaverton, Oregon, and GigaBit Logic of Newbury Park, California. TriQuint had been making the chips designed by Gazelle's researchers, and its name was retained by the new company, which last year had a turnover of about $\$ 30$ million and showed a small profit.

The US government continues to receive royalties from the sale of chips designed under the original agreement with Gazelle, although TriQuint is no longer receiving any support from ARPA (the ' $D$ ' was dropped last month as part of the Clinton administration's promise to shift spending from the military to the civilian sectors). Spencer Brown, TriQuint's executive vice president and chief financial officer, says that the federal contribution enabled Gazelle to continue improving its technology and that the company expects increased demand for its products if a national information superhighway becomes a reality (see Nature 362, 582; 1993).

Fields is confident that Prabhakar, who now directs ARPA's \$300-million microelectronics technology office, can run an agency whose budget is expected to quadruple to $\$ 1.4$ billion in the next four years. But he warns his former coworker that her every move will be scrutinized.

"If one tries to help every industry, you spread yourself too thin", says Fields. "But if you favor those with the best chance of succeeding, then you leave yourself open to political attacks from those left out."

The Clinton administration hopes to prevent that from happening. Speaking last week at a conference entitled "New Directions in Technology Policy", Commerce secretary Ron Brown said that "a raging debate about the proper relationship between industry and the government" is over and that the government is "ready to work hand-in-hand with industry to strengthen the US economy". If nothing else, Prabhakar's appointment seems to be proof of that commitment.

Frederic Golden \& Jeffrey Mervis

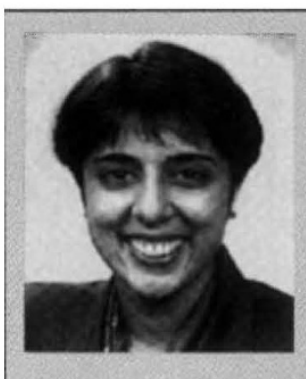

Arati Prabhakar was born in India and moved to the United States at the age of 3 . Trained as an electrical engineer she received her $\mathrm{PhD}$ in applied physics from

California Institute of Technology in Pasadena and moved to Washington in 1984 to become a congressional fellow at the Office of Technology Assessment.

In 1986 she joined the Defense Advanced Research Projects Agency (DARPA), first as programme manager of the electronics sciences division of the Defense Sciences Office and, later as deputy director of the office, where she negotiated the agreement with Gazelle (see left). Two years ago, she was asked to head a new office on microelectronics technology, with an annual budget of $\$ 300$ million.

Although Prabhakar has declined to talk to the media until after she is confirmed by the US Senate, three years ago she described her job at DARPA as one of "making sure that things happen. My goal is to get the technology out of the lab and into the hands of others." That statement is also an apt description of what she will be asked to do at NIST.

F.G. \& J.M. 